\title{
Shear in plain, bed joint reinforced, and post- tensioned masonry
}

\author{
Shelley L. Lissel, Nigel G. Shrive, and Adrian W. Page
}

\begin{abstract}
Masonry is cost competitive on a life cycle basis with other forms of construction, and should therefore be considered as a structural material more frequently by both architects and engineers. Post-tensioned geometric sections of masonry are structurally efficient wall systems. Post-tensioning with carbon fibre reinforced polymer (CFRP) is an attractive solution to potential corrosion problems with unbonded tendons. Tests on CFRP post-tensioned diaphragm walls have revealed that shear strength in prestressed masonry is an area deserving more study and improvement. The tests also showed that the bonding pattern of the masonry at the web-flange junction can have a substantial effect on the resulting strength of that connection. A test series to evaluate the effects of prestress force and bed reinforcement on shear strength has been carried out and a summary of the results is presented here. Tests to determine the effect of bonding pattern on the strength of the web-flange connection have also been conducted.
\end{abstract}

Key words: post-tensioning, masonry, shear, FRP tendons, corrosion-free.

Résumé : La maçonnerie, sur la base d'un cycle de vie avec d'autres formes de construction, est compétitive en terme de coût et devrait donc être considérée comme matériau structural plus fréquemment, et ce autant par les architectes que par les ingénieurs. Des sections géométriques de maçonnerie post-tendues constituent des systèmes de paroi efficace d'un point de vue structural. La post-tension avec des PRFC est une solution attrayante aux problèmes potentiels de corrosion avec des barres non liées. Des tests sur des parois à diaphragme post-tendues avec des PRFC ont révélé que la résistance au cisaillement de la maçonnerie pré-tendue est un domaine qui mérite plus d'étude et d'amélioration. Les tests montrent aussi que le mode de liaison de la maçonnerie à la jonction aile-extrémité peut avoir un effet substantiel sur la résistance résultante de cette connexion. Une série de tests pour évaluer les effets de la force de précontrainte et du lit de renforcement sur la résistance au cisaillement a été conduite, et un résumé des résultats est présenté ici. Des tests pour déterminer l'effet du mode de liaison sur la résistance de la connexion aile/extrémité ont aussi été entrepris.

Mots clés : post-tension, maçonnerie, cisaillement, barres de PRF, sans corrosion

Traduit par la Rédaction.

\section{Introduction}

Recent studies (e.g., Garrity and Nicholl 1994; Kirk 1996) have shown that masonry is an economic construction material. The former demonstrates that where the aesthetic value of a brick finish is desired, load bearing masonry is the most cost-effective retaining wall; the latter author shows loadbearing blockwork with brick veneer is less expensive on a life-cycle basis than three other wall types (glass curtain, metal panel, and metal stud). Post-tensioning of masonry diaphragm walls produces a robust and efficient structural

Received February 21, 2000.

Revised manuscript accepted May 26, 2000.

S.L. Lissel and N.G. Shrive. ${ }^{1}$ Department of Civil Engineering, The University of Calgary, Calgary, AB T2N 1N4, Canada.

A.W. Page. Faculty of Engineering, Department of Civil, Surveying, and Environmental Engineering, University of Newcastle, Callaghan (2308), NSW, Australia.

Written discussion of this article is welcomed and will be received by the Editor until February 28, 2001.

${ }^{1}$ Author to whom all correspondence should be addressed: (e-mail: shrive@ucalgary.ca). form, with the added benefit of aesthetic attractiveness. Such walls have been used as retaining walls, bridge abutments, in leisure centres, and religious meeting halls with considerable success. A common problem among all applications is protection of the steel tendons from corrosion. Hanlon (1970), for example, describes placing the tendons inside well-sealed garden hose to post-tension 80-100-year-old church steeples in New Zealand. Foster (1970) used standard prestressing wire in ducts to post-tension a water tank in the U.K. The ducts were incorporated in the walls during construction. Bradshaw et al. (1982) used plastic ducts to protect Macalloy bars, whereas Curtin et al. (1982) treated the rods with a proprietary paste (Denso) before wrapping with Denso tape. The VSL method has the tendons running through grease-filled ducts (Ganz 1996) in applications in the U.S.A. and Switzerland. Garrity (1995) discusses the need for extra care with protection methods in masonry because masonry tends not to have the same alkaline environment as portland cement concrete to provide the same longterm protection to embedded steel. The advantage of a simple, non-corroding post-tensioning system is therefore evident.

Single wythe masonry is not the most efficient structural system for resisting the loads typically applied to walls, particularly high walls. "Geometric" cross sections of masonry 
Fig. 1. Schematic cross sections of $(a)$ a diaphragm wall, $(b)$ a fin wall, and (c) a channel-shaped wall.

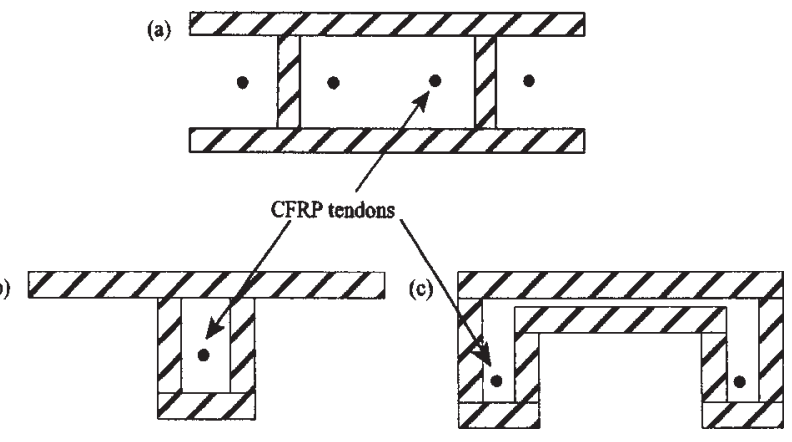

provide much better resistance, and those most commonly used are the diaphragm, fin, and channel shapes (see Fig. 1). Each type can be post-tensioned and examples are provided by Allen (1986) (diaphragm), Curtin et al. (1989) (fin), and Shaw et al. (1988) (channel). A diaphragm wall, with the two wythes separated by a distance of two bricks, posttensioned to a low stress of 1.5 MPa has a flexural cracking moment of resistance 75 times that of a plain masonry cavity wall.

In Calgary, diaphragm masonry walls post-tensioned with both carbon fibre reinforced polymer (CFRP) and steel tendons in the laboratory have demonstrated that the technique is viable. Carbon fibre reinforced polymer tendons were used in some tests to develop techniques and understanding for prestressing with these new materials. The tendons were stressed with the anchorage described by Sayed-Ahmed and Shrive (1998), although there is the potential to use a completely metal-free system by using the ultra high performance concrete anchorage described by Campbell et al. (2000). All walls stressed with CFRP tendons have been diaphragm walls, post-tensioned with four $8 \mathrm{~mm}$ diameter Leadline $^{\mathrm{TM}}$ tendons. The first wall tested was subject to a thermal (freezing) test, two flexural tests, and a racking shear test. The results of these tests are described extensively in other publications (Sayed-Ahmed et al. 1999; Lissel et al. 1999; Lissel et al. 1998).

A design method based on the Canadian and other codes has been proposed that includes allowance for losses in effective prestress due to creep and shrinkage in masonry, relaxation of the tendons, and thermal effects (Sayed-Ahmed et al. 1999). During design of a retaining wall with this method, it became clear that shear strength was the limiting factor in the design. Hence, further diaphragm walls were tested with different bonding patterns to see how the bonded web-flange connections altered the shear performance. Panels with different bed reinforcements were tested to determine $(a)$ what effect prestressing had on the shear performance and $(b)$ if bed reinforcement would be an effective method of improving shear strength. Specimens with $\mathrm{H}-$ shaped cross section were also tested to assess the strength of the web-flange connection.

\section{Shear in prestressed masonry}

\section{Diaphragm wall tests}

Tests were conducted on two $3 \mathrm{~m}$ high walls, one with tied and the other with bonded brickwork patterns (Fig. 2).
Fig. 2. Bonding patterns for diaphragm walls: (a) tied wall and (b) bonded wall.

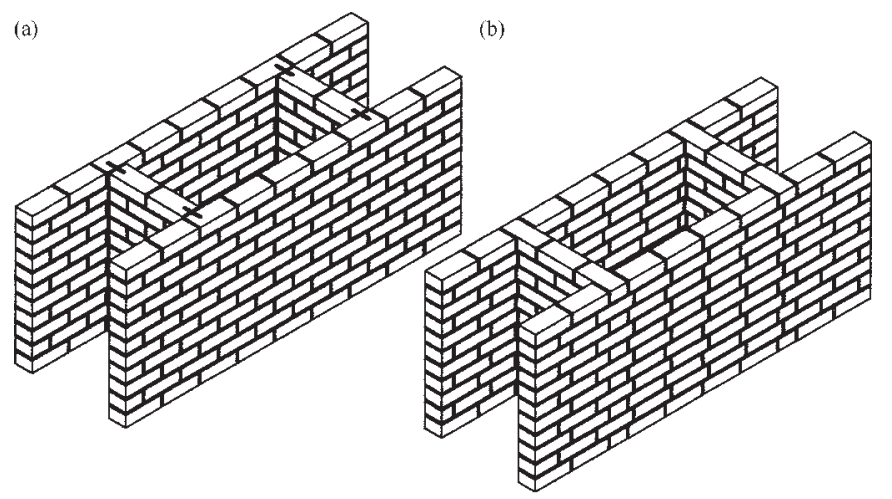

There is a continuous vertical mortar joint in the tied wall, with running bond in the flanges. In the bonded wall, the webs and flanges interlock in the brickwork requiring $1 / 3$ running bond in the flanges with variation at each web. The same masonry was used in each wall and had a 28-day characteristic strength $\left(f_{\mathrm{m}}^{\prime}\right)$ of $12 \mathrm{MPa}$. The loading scheme is shown in Fig. 3. The loading was designed to simulate increasing load to the base of the wall as would occur in a retaining wall. The applied load that caused shear cracking in the webs was $90 \mathrm{kN}$ in the first test and $100 \mathrm{kN}$ in the second. These loads correspond roughly to equivalent soil unit weights of 37 and $41 \mathrm{kN} / \mathrm{m}^{3}$, respectively.

The tied wall was loaded until shear cracks had propagated in the webs from the location of the lower loading beam. Cracks are shown in Fig. 4. The wall separated from the base on the loaded side of the wall at approximately $75 \mathrm{kN}$ of applied load, corresponding to a moment at the base of $84 \mathrm{kN} \cdot \mathrm{m}$ (Fig. 5, bond broken between the mortar and the concrete base). The first shear crack propagated from the lowest load point at an applied load of $90 \mathrm{kN}$. The shear stress in the section according to the Canadian code is given in Table 1.

The bonded wall behaved quite differently. With the loading arrangement shown in Fig. 3, no cracking occurred until the applied load reached $77 \mathrm{kN}$, at which point the wall lifted off the base beam in flexure just as the tied wall had done (Fig. 5). Testing continued until the load reached $93 \mathrm{kN}$. No shear cracks were observed. However, the top of the wall had displaced almost $100 \mathrm{~mm}$, and the force in each tendon had increased by $15 \mathrm{kN}$ because the wall was rotating as a rigid body about the compression toe.

To increase the shear force to moment ratio, the loading configuration was changed to apply load to the bottom two loading points only. The actuator was positioned to apply load at the third point of the lower spreader beam. Two thirds of the applied load were therefore directed to the lowest load point and one third to the point above. Shear cracks in the webs occurred at an applied load of $100 \mathrm{kN}$ (stress at section given in Table 1). The cracks were stepped but also passed through a few bricks (Fig. 4). Testing continued until a hinge formed in the tensile flange of the wall with flexural cracks developing between the fifth and sixth courses and at the level of the first loading beam (Fig. 6). These cracks occurred at applied loads of 106 and $109 \mathrm{kN}$, respectively. On unloading, these flexural cracks closed and the wall returned 
Fig. 3. Schematic of the loading system for the shear tests on the tied and bonded walls, along with the shear distribution.
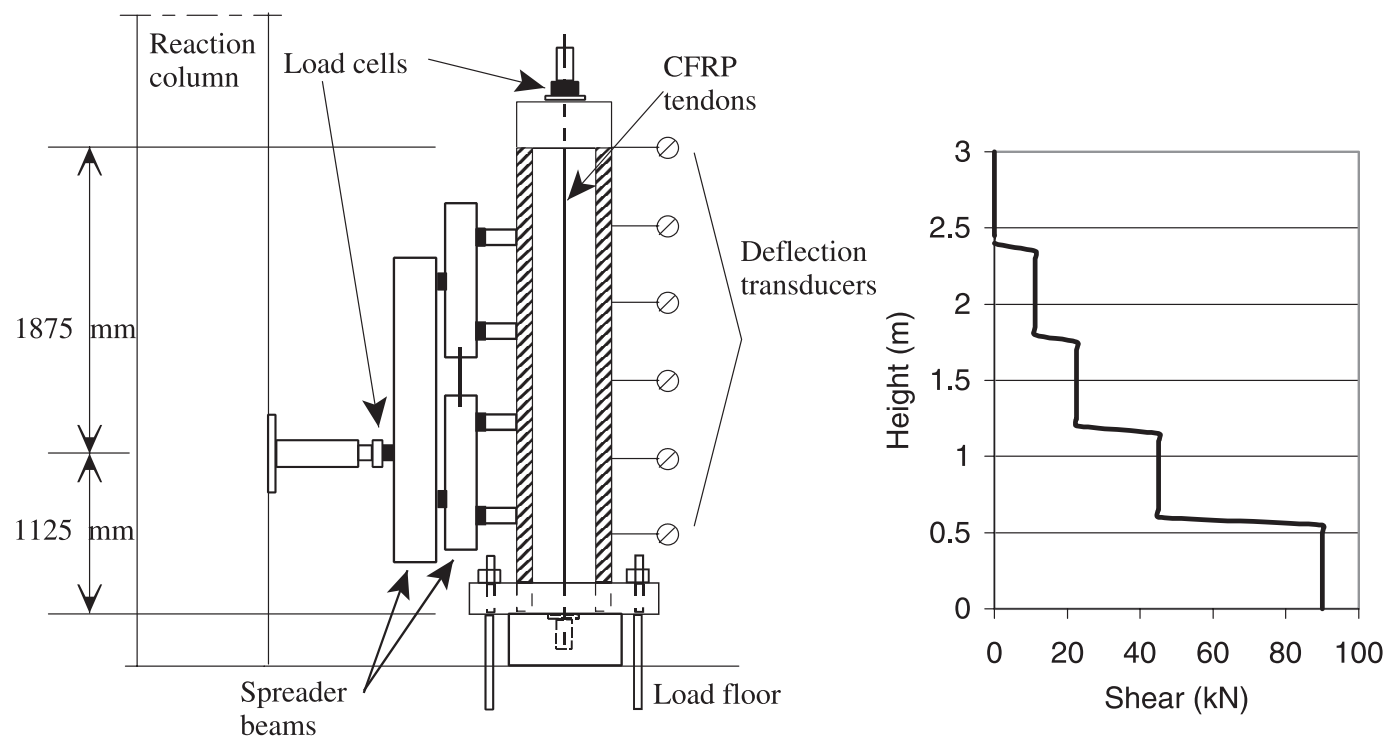

to its original shape. Interestingly, the crack at the base of the wall was barely visible throughout the second test, even though the bond there had been broken in the initial test on this wall.

These tests indicated that prestressing and bonding pattern of the web-flange connection affect the shear strength of masonry. A design procedure for CFRP prestressed diaphragm walls was proposed previously (Sayed-Ahmed et al. 1999). In development of that design procedure, shear strength was examined for the cases of walls uncracked and cracked in flexure. The British and Canadian codes were considered. Table 1 summarizes the test data and values predicted by the Canadian code CSA-S304.1-94 (CSA 1994). Shear capacity allowed in the current Canadian code is quite low, since no allowance is made for any contribution to increased shear resistance from the prestressing force. Clause 11.5.4 of CSA-S304.1-94 (for out-of-plane shear) could be loosely interpreted to apply to prestressed members if active prestress is taken to be equivalent to dead load. However, by strictly following the code, the limiting factor in the design of a masonry structure such as a retaining wall is the shear strength. Additional increases in shear area, and thus capacity, could be obtained by either increasing the thickness or the number of webs. However, both of these options are economically unappealing, especially when post-tensioning has been used to increase the cracking moment of resistance of the wall.

Both the Canadian CSA-S304.1-94 (CSA 1994) and British BS-5628 (BSI 1995) codes instruct the designer to calculate the shear stress simply by dividing the shear force by the cross-sectional area of the shear resisting masonry. The Australian code AS-3700 (SA 1998) includes a factor related to the aspect ratio of the wall, as does the Canadian code for low aspect ratio shear walls. However, none of the codes takes the angle of the shear crack into consideration. A simple analysis accounting for the failure angle shows that the two cases here are more different than the code equations would lead one to believe. Given that the wall lifts off the base, a free-body diagram of the masonry is as shown in
Fig. 7a. $T$ is the pre-stressing force, and the equations of equilibrium provide for the tied wall:

$$
\begin{aligned}
& C=T+W \\
& V=P \\
& e C=\frac{P}{2}\left(\frac{h}{5}\right)+\frac{P}{4}\left(\frac{2 h}{5}\right)+\frac{P}{8}\left(\frac{3 h}{5}\right)+\frac{P}{8}\left(\frac{4 h}{5}\right)=\frac{3 P h}{8}
\end{aligned}
$$

For the bonded wall, Fig. $7 b$ gives the free-body diagram and the equations of equilibrium are

$$
\begin{aligned}
& C=T+W \\
& V=P \\
& e C=\frac{2 P}{3}\left(\frac{h}{5}\right)+\frac{P}{3}\left(\frac{2 h}{5}\right)=\frac{4 P h}{15}
\end{aligned}
$$

Once the shear crack has formed, Fig. $7 c$ provides the freebody diagram of the bottom section of masonry. The following are obtained:

$$
\begin{aligned}
N & =-V \sin \theta+C \cos \theta \\
S & =V \cos \theta+C \sin \theta
\end{aligned}
$$

In the case of the tied wall, $C=335 \mathrm{kN}$ and $\theta=26^{\circ}$, giving $S=228 \mathrm{kN}$ and $N=262 \mathrm{kN}$. The effective coefficient of friction, $S / N$, equals 0.9 . For the bonded wall, $C=307 \mathrm{kN}$ and $\theta=38^{\circ}$, giving $S=268 \mathrm{kN}$ and $N=180 \mathrm{kN}$. The effective coefficient of friction, $S / N$, equals 1.5. Calculation of $e$ for both walls yields a moment arm of $300 \mathrm{~mm}$ for the tied wall and $260 \mathrm{~mm}$ for the bonded wall. Note that for the tied wall the location of the compression force is slightly beyond the outside edge of the flange $(1.7 \%)$. This is possibly due to the effects of the rotation of the wall not being considered in eq. [1]. The location of the compression force for the bonded wall is near the centre of the compression flange, which is quite reasonable, since there was very little rotation in this wall.

It appears from this analysis that the bonding method at the web-flange interface is of considerable importance and 
Fig. 4. Shear cracks in the webs of (a) the tied wall (cracks enhanced with felt pen) and $(b)$ the bonded wall. Load was applied from left to right at the level indicated.
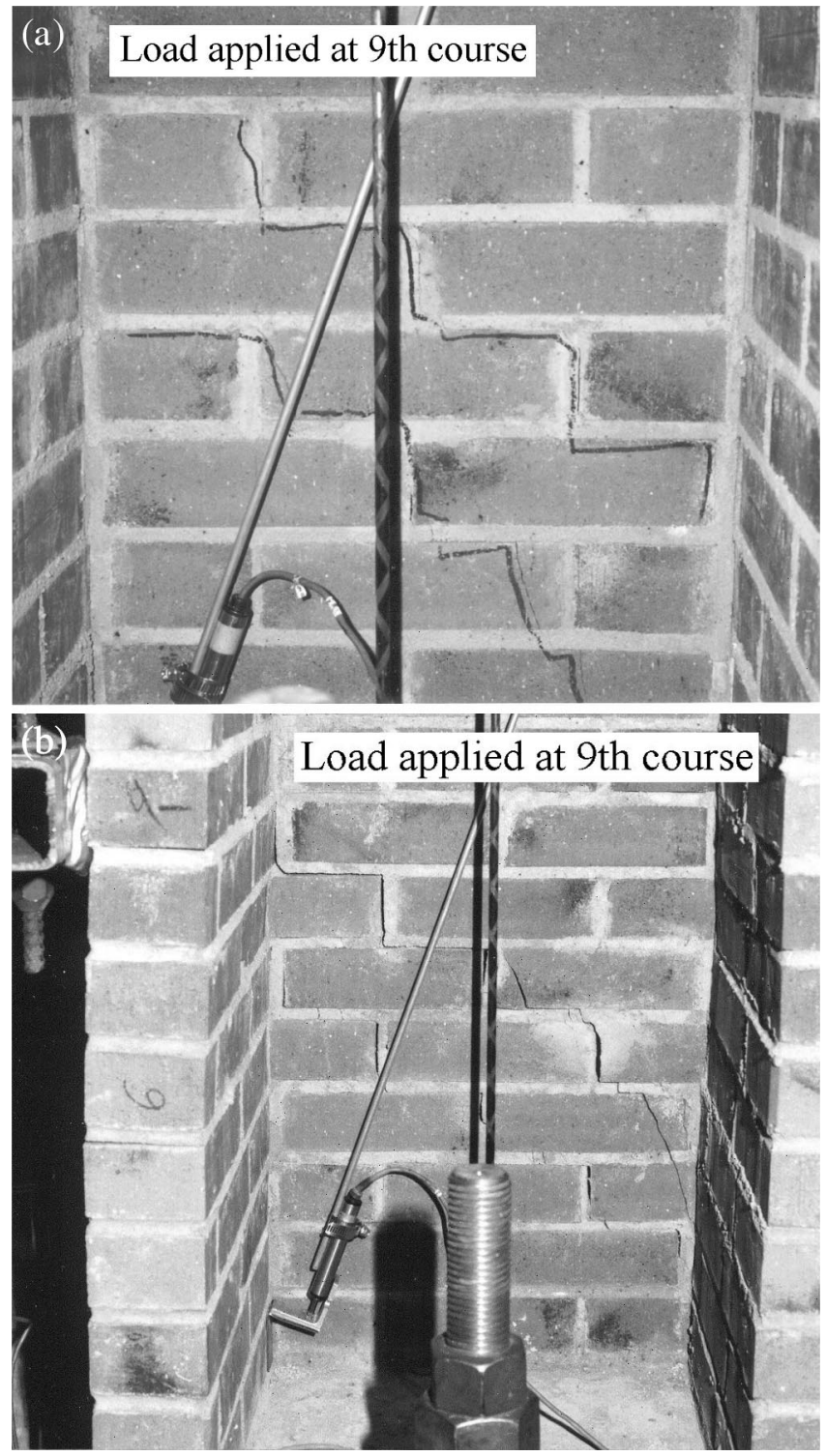

that the normal force across the plane of failure will influence the magnitude of shear that can be carried. For shear walls, the current Canadian code specifies the design shear strength as a function of the ratio of $M$ to $V$. Short, squat walls will have higher design shear strength than tall, narrow shear walls subject to the same shear force, as provided for in the Australian code and in clause 11.5.3.2 of the Canadian code. While this is logical, the actual mode and angle of cracking is not considered. For beams, in the Canadian code, shear strength is related to beam depth in blockwork but not in brickwork. In some senses, the retaining wall is a vertical beam: but again in beams, the angle of the crack is not considered. Indeed, if the tested walls are treated as beams, the unfactored shear strength would be $0.28 \mathrm{MPa}$, substantially lower than all values in Table 1! It therefore appears that the subject of shear failure in masonry structures warrants further thought and study.
Fig. 5. The $(a)$ tied and $(b)$ bonded walls rotating off the base in flexure.
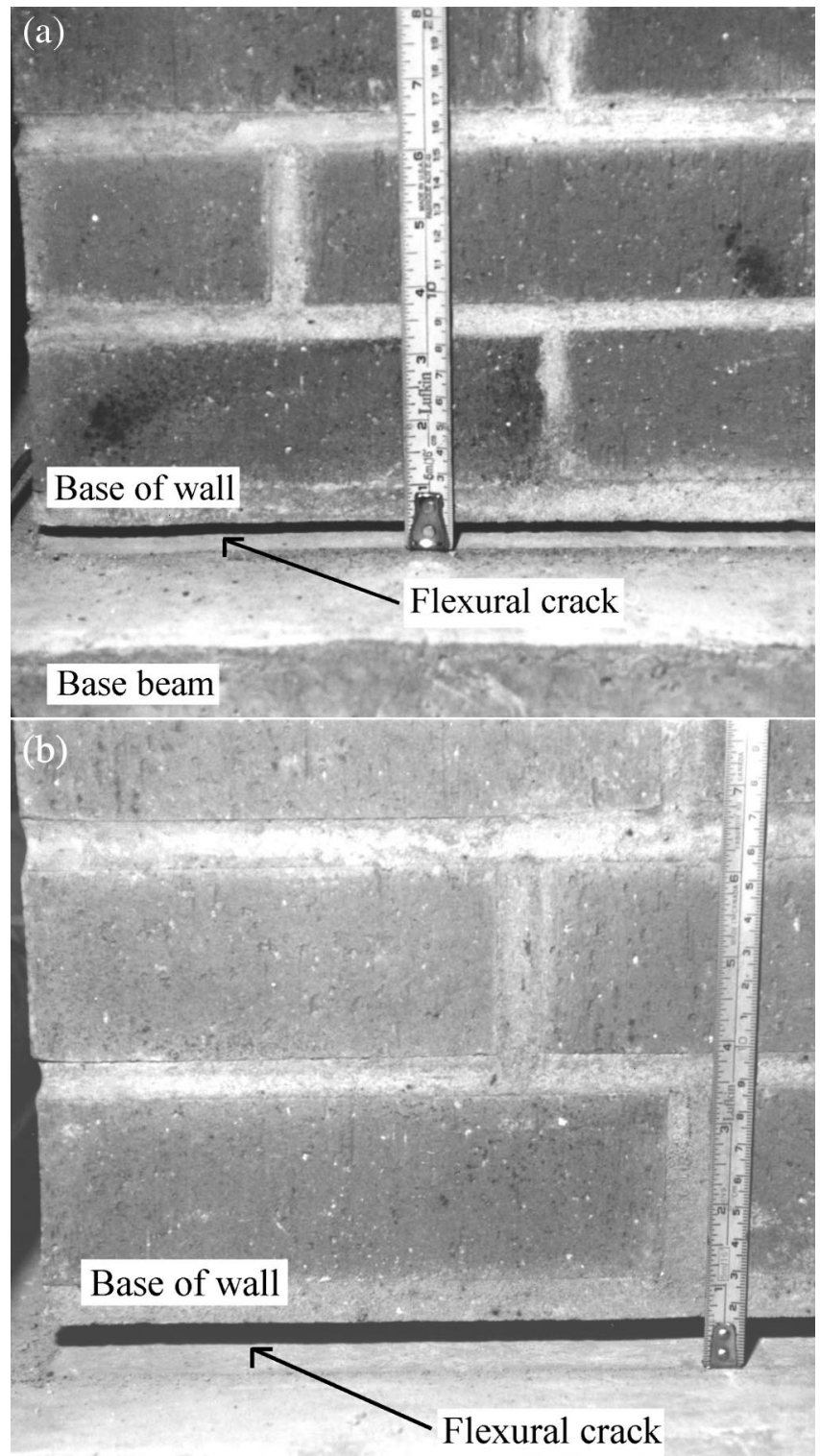

\section{Base beam}

\section{Panel tests}

In an attempt to understand and quantify the influence of prestressing and bed reinforcement on the shear strength in masonry, diagonal tension (shear) tests were conducted on 39 brick panels at the University of Newcastle, Australia, in accordance with ASTM E519. The panels were $1.2 \mathrm{~m}$ high (14 courses) and $1.2 \mathrm{~m}$ wide. They were constructed of standard Australian bricks $(235 \times 110 \times 75 \mathrm{~mm})$ and 1:1:6 mortar, 28-day characteristic strength $\left(f_{\mathrm{m}}^{\prime}\right)$ of $7.9 \mathrm{MPa}$, each with one of four types of bed joint reinforcement. The panels were tested under three levels of prestressing $(0,0.75$, and 1.5 MPa). The types of reinforcement were mild steel ladder type reinforcement, geogrid fabric reinforcement, and two types of glass fibre reinforced polymer (GFRP) rein- 
Table 1. Shear stresses (unfactored) from tests, code equations, and proposed equation.

\begin{tabular}{|c|c|c|c|c|c|c|c|c|}
\hline Wall & $\begin{array}{l}\text { Height }^{a} \\
(\mathrm{~m})\end{array}$ & $\begin{array}{l}\text { Shear at } \\
\text { section } \\
(\mathrm{kN})\end{array}$ & $\begin{array}{l}\text { Shear } \\
\text { stress }^{b} \\
(\mathrm{MPa})\end{array}$ & $M / V t$ & $\begin{array}{l}\mathrm{v}_{\mathrm{m}_{0}} \\
(\mathrm{eq} .[5]) \\
(\mathrm{MPa})\end{array}$ & $\begin{array}{l}\mathrm{v}_{\mathrm{m}}{ }^{c} \\
(\mathrm{eq} .[5]) \\
(\mathrm{MPa})\end{array}$ & $\begin{array}{l}\mathrm{v}_{\mathrm{m}} \\
\text { (eq. [6]) }\end{array}$ & $\begin{array}{l}\text { Avg. } \\
(\mathrm{MPa})\end{array}$ \\
\hline \multirow[t]{3}{*}{ Tied } & 0.6 & \multirow{3}{*}{90} & \multirow{3}{*}{0.85} & $1.78^{d}$ & 0.55 & 0.74 & 1.06 & \multirow{3}{*}{0.99} \\
\hline & 0.4 & & & & 0.55 & 0.74 & 0.93 & \\
\hline & 0.4 & & & $2.46^{d}$ & 0.55 & 0.74 & 0.93 & \\
\hline \multirow[t]{3}{*}{ Bonded } & 0.45 & \multirow{3}{*}{100} & \multirow{3}{*}{0.94} & $1.18^{d}$ & 0.55 & 0.72 & 1.04 & \multirow{3}{*}{1.00} \\
\hline & 0.15 & & & & 0.55 & 0.72 & 0.96 & \\
\hline & 0.15 & & & $2.27^{d}$ & 0.55 & 0.72 & 0.96 & \\
\hline
\end{tabular}

\footnotetext{
${ }^{a}$ The locations listed are the tops and bottoms of the shear cracks in the respective walls.

${ }^{b}$ The shear stress was determined from V/bt, where the product $b t$ is the cross-sectional area of the webs.

${ }^{c}$ Clauses 11.5.3.1 and 11.5.4 apply for in-plane and out-of-plane shear, respectively. For this discussion they both simplify to the form given in eq. [5].

${ }^{d}$ The minimum and maximum limits on this ratio for eq. [5] are 0.25 and 1 , respectively.

${ }^{e}$ Value is the maximum due to the limit on $f_{\mathrm{td}}$ in eq. [6].
}

Fig. 6. A hinge developing in the tensile (loaded) flange of the bonded wall.

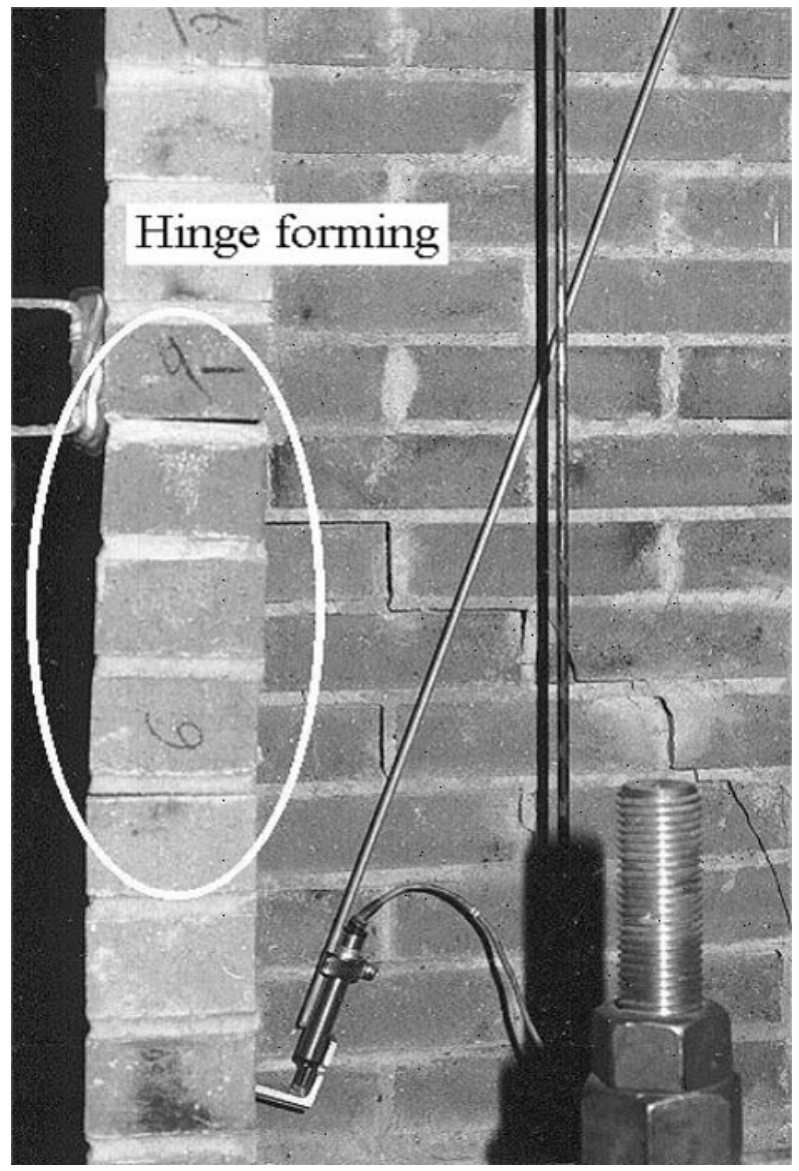

forcement, as shown in Fig. 8. Three panels were constructed for each combination of prestressing and steel or geogrid reinforcement. Only enough of each type of GFRP was available to construct two panels for each combination. Also, the limited amount of GFRP required that a slightly different reinforcing pattern be followed. While the steel and geogrid reinforcements were placed in every second bed joint (1st, 3rd, 5th, 7th, 9th, 11th, and 13th joints), the GFRP panels were only reinforced in the 4 th, 7 th, and 10th bed
Fig. 7. Free-body diagrams of $(a)$ the tied wall, $(b)$ the bonded wall, and $(c)$ the lower cracked section of the wall. (a)

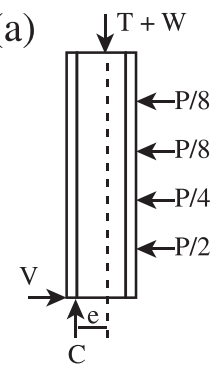

(b)

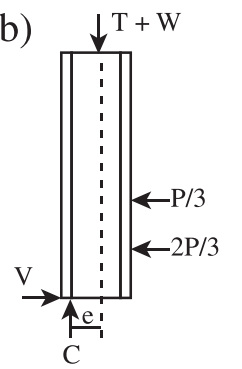

(c)

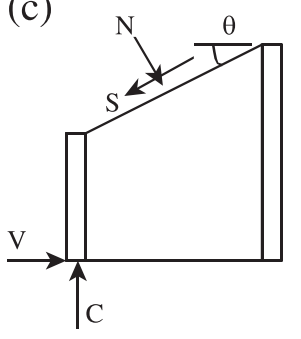

joints. The testing arrangement including the prestressing frame is shown in Fig. 9.

The panels, their corresponding reinforcement type, amount of applied prestressing, ultimate load, and type of failure are listed in Table 2. Most unprestressed panels failed in diagonal tension (usually called shear) with stepped cracks through the joints. When prestressing was applied, the cracks started to follow a more direct path through bricks as well as through joints. Typical failure patterns are illustrated in Fig. 10. At the higher prestress level (1.5 MPa) a few of the panels failed by local compression in the loading shoe, possibly because of weak bricks. Under zero prestress, the GFRP reinforced panels failed by slipping along the 4th bed joint, probably because of the increased stiffness of the middle portion of the panel and the tendency for failure to occur along the weakest path. Once prestress was applied, this type of failure did not occur because of the increased strength of the joints from the applied compression. The test data are plotted by reinforcement type in Fig. 11. In this figure the shear strength is determined according to the ASTM E519 (the shear load divided by the shear area). The equations for the best-fit lines from each series are also presented in this figure. The lines are all similar, indicating that the type of reinforcement seems to have little influence on the failure (cracking) load in this type of test. The post-cracking behaviour, however, was significantly affected by the type of reinforcement. A more detailed discussion of the failure patterns and the post-cracking behaviour is given in Lissel et al. (2000). The results call into question the validity of the test as a relevant shear test, since the stress state on a joint is un- 
Fig. 8. Materials used in the ASTM E519 panel tests.

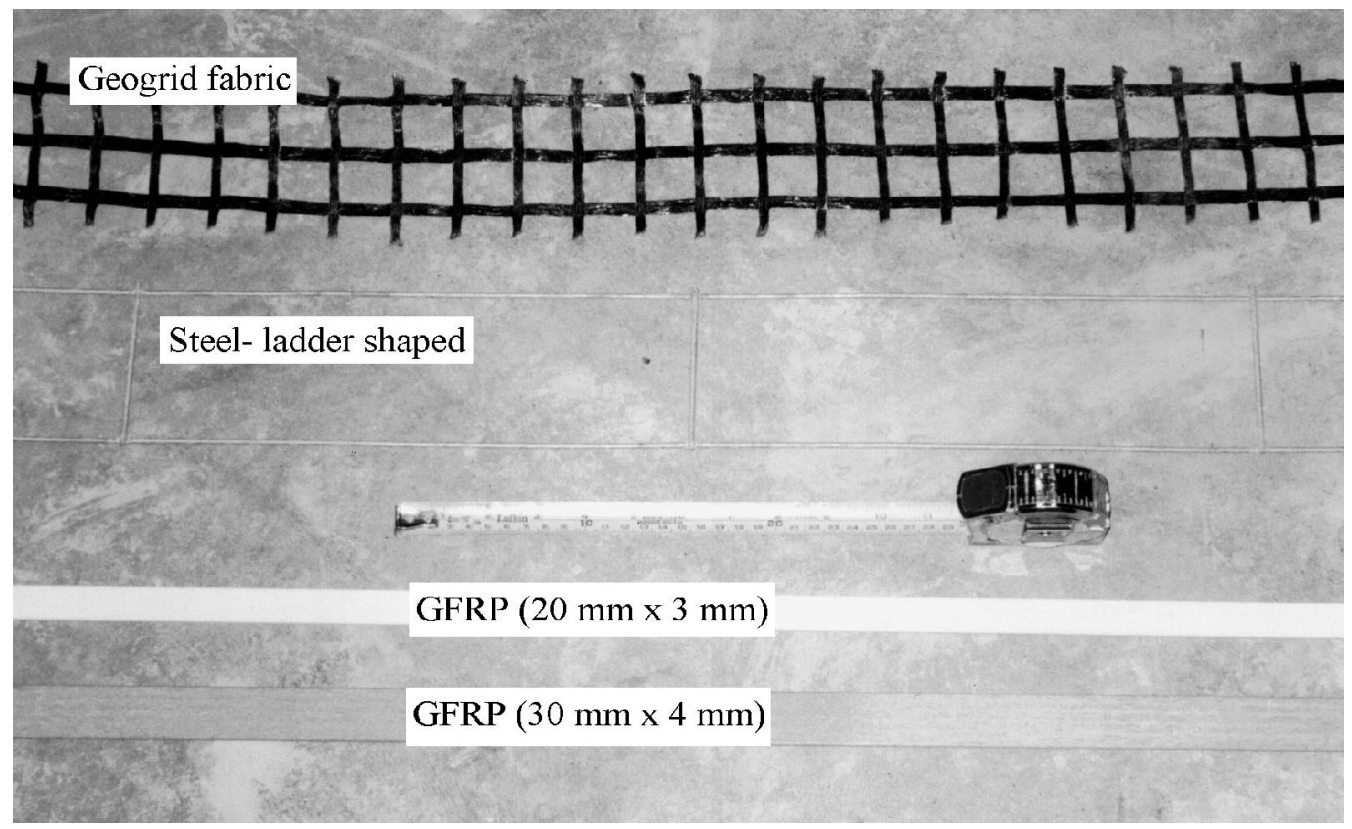

Fig. 9. Schematic drawing of the ASTM E519 test arrangement including prestressing frame.

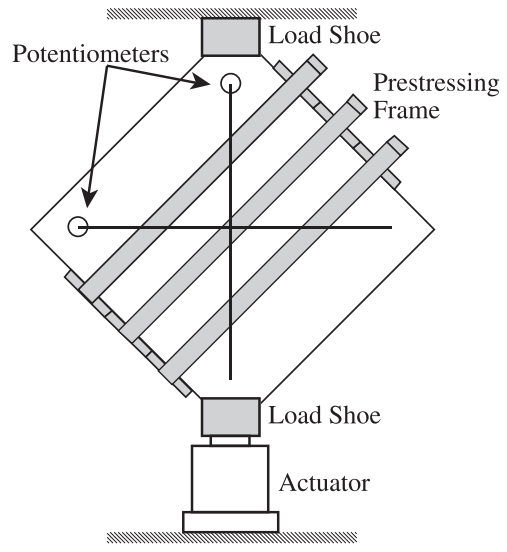

like that normally found in masonry. Also, as the prestress was increased, the crack occurred closer and closer to the line of physical symmetry. This reflects a splitting tensilecompressive failure rather than a shear failure. Stresses normal and parallel to the bed joint were therefore calculated based on the stress state that develops in a splitting tension test and assuming that failure is initiated at a point on the line of symmetry located a distance D/5 from the load shoe. For each level of prestress normal to the bed joint, a fixed relationship exists between the normal and shear stresses. The strength of each specimen therefore appears as a point on the resulting straight line. Results of this analysis are plotted in Fig. 12 in terms of the normal and shear stresses on the bed joint. At zero shear, the lines pass through 0 , 0.75 , and 1.5 MPa compression on the bed joint, respectively, reflecting the three levels of prestress. Linear regression on the three mean values provides the equation:

$$
\mathrm{v}_{\mathrm{m}}=0.71 f_{\mathrm{p}}+\mathrm{v}_{\mathrm{m}_{0}}
$$

where $v_{\mathrm{m}}$ is the total shear strength, $f_{\mathrm{p}}$ is the normal stress on the bed joint including that due to prestress, and $v_{\mathrm{m}_{0}}$ is the shear strength with no prestress applied (0.85 $\mathrm{MPa}$ for this data set). Also plotted in Fig. 12 are the limits on shear strength for shear walls according to the code (CSA S304.11994).

Clause 11.5.3.3:

$$
\mathrm{v}_{\mathrm{m}_{0}}=0.16\left(2-\frac{M}{V t}\right) \sqrt{f_{\mathrm{m}}^{\prime}} \quad 0.25 \leq \frac{M}{V t} \leq 1
$$

Clause 11.5.3.1:

$$
\mathrm{v}_{\mathrm{m}}=\mathrm{v}_{\mathrm{m}_{0}}+0.25 f_{\mathrm{p}} \quad \mathrm{v}_{\mathrm{m}} \leq 0.4 \sqrt{f_{\mathrm{m}}^{\prime}}
$$

Clause 11.5.3.3 provides the limits for $v_{m_{0}}$, while clause 11.5.3.1 allows for some addition to the shear strength $\left(0.25 f_{\mathrm{p}}\right)$ from axial compressive load based on $85 \%$ of the dead load. For purposes of this comparison, the limits plotted in Fig. 12 assume that $f_{\mathrm{p}}$ is due to the prestressing force. Maximum and minimum limits are plotted, since equivalent $M$ and $V$ cannot be calculated for the panel tests. Note that there is a maximum value of $\mathrm{v}_{\mathrm{m}}$ of $1.12 \mathrm{MPa}$ for this masonry that governs when $f_{\mathrm{p}}$ is $1.3 \mathrm{MPa}$ or more. Figure 12 also shows the test data in comparison with the proposed equation of Sayed-Ahmed et al. (1999):

$$
\begin{array}{ll}
\mathrm{v}_{\mathrm{m}}=\sqrt{f_{\mathrm{td}}^{2}+f_{\mathrm{p}} f_{\mathrm{td}}} \quad & f_{\mathrm{td}}=1.3-0.275 M / V t \\
& 0.2 \leq f_{\mathrm{td}} \leq 0.75
\end{array}
$$

The code equations may be seen to be conservative when extra compression from active prestress is applied to the masonry. Equation [6] produces a better correlation to the test data but still does not follow the trend shown by the data. The results (Figs. 11 and 12) suggest that further study on the shear behaviour of masonry is necessary to obtain a better understanding of the behaviour in general and also to investigate the influence of prestress beyond 1.5 $\mathrm{MPa}$. 
Table 2. List of shear panels, ultimate loads, and failure modes.

\begin{tabular}{|c|c|c|c|c|}
\hline Panel $^{a}$ & $\begin{array}{l}\text { Prestress } \\
(\mathrm{MPa})\end{array}$ & $\begin{array}{l}\text { Ultimate } \\
\text { load } \\
(\mathrm{kN})\end{array}$ & $\begin{array}{l}\text { Shear } \\
\text { strength } \\
(\mathrm{MPa})\end{array}$ & Failure mode \\
\hline $\mathrm{P}-2$ & 0.75 & 302 & 1.62 & Shear \\
\hline P-4 & 0.75 & 226 & 1.22 & Shear \\
\hline P-6 & 0.75 & 230 & 1.24 & Shear \\
\hline P-7 & 0 & 222 & 1.19 & Shear \\
\hline P-8 & 0 & 136 & 0.73 & Shear \\
\hline P-9 & 0 & 115 & 0.62 & Shear \\
\hline $\mathrm{P}-1$ & 1.5 & 360 & 1.94 & Shear \\
\hline P-3 & 1.5 & 309 & 1.66 & Shear \\
\hline $\mathrm{P}-5^{b}$ & - & - & - & - \\
\hline $\mathrm{GG}-4^{b}$ & 0.75 & - & - & - \\
\hline GG-6 & 0.75 & 248 & 1.33 & Shear \\
\hline GG-8 & 0.75 & 262 & 1.41 & Shear \\
\hline GG-5 & 1.5 & 386 & 2.08 & Shear \\
\hline GG-7 & 1.5 & 382 & 2.05 & Shear \\
\hline GG-9 & 1.5 & 280 & 1.51 & Compression $^{c}$ \\
\hline GG-1 & 0 & 112 & 0.6 & Shear \\
\hline GG-2 & 0 & 97 & 0.52 & Shear \\
\hline GG-3 & 0 & 92 & 0.49 & Shear \\
\hline G60-1 & 0.75 & 238 & 1.28 & Shear \\
\hline G60-3 & 0.75 & 320 & 1.72 & Shear \\
\hline G60-2 & 1.5 & 285 & 1.53 & Shear \\
\hline G60-4 & 1.5 & 342 & 1.84 & Compression $^{c}$ \\
\hline G60-5 & 0 & 204 & 1.1 & Joint $^{c}$ \\
\hline G60-6 & 0 & 114 & 0.61 & Joint $^{c}$ \\
\hline G120-4 & 0.75 & 267 & 1.44 & Shear \\
\hline G120-6 & 0.75 & 238 & 1.28 & Shear \\
\hline G120-1 & 1.5 & 381 & 2.05 & Shear \\
\hline G120-2 & 1.5 & 361 & 1.94 & Shear \\
\hline G120-3 & 0 & 153 & 0.82 & Joint $^{c}$ \\
\hline G120-5 & 0 & 157 & 0.84 & Joint $^{c}$ \\
\hline S-5 & 0.75 & 191 & 1.03 & Shear \\
\hline S-7 & 0.75 & 326 & 1.75 & Shear \\
\hline S-9 & 0.75 & 357 & 1.92 & Shear \\
\hline$S-1$ & 1.5 & 368 & 1.98 & Shear \\
\hline S-2 & 1.5 & 260 & 1.4 & Shear \\
\hline S-3 & 1.5 & 333 & 1.79 & Shear \\
\hline S-4 & 0 & 99 & 0.53 & Shear \\
\hline S-6 & 0 & 167 & 0.9 & Shear \\
\hline$S-8$ & 0 & 237 & 1.27 & Shear \\
\hline
\end{tabular}

${ }^{a}$ Panels were numbered in order of casting and indicate the type of reinforcing used: $\mathrm{P}=$ plain (no reinforcement), $\mathrm{GG}=$ geogrid reinforcement, G60 = GFRP with area $60 \mathrm{~mm}^{2}, \mathrm{G} 120=$ GFRP with area $120 \mathrm{~mm}^{2}, \mathrm{~S}=$ steel reinforcement.

${ }^{b}$ Panel P-5 broke during set up and panel GG-4 was tested but the data were lost.

${ }^{c}$ These are lower bound values, since compression or joint failures prevented the ultimate shear strength from being reached.

\section{Web-flange connection tests}

In the tests on diaphragm walls, the bond pattern at the web-flange interface was the only thing differentiating the
Fig. 10. Typical shear failure patterns for $(a)$ an unprestressed panel (reinforced panels had similar crack patterns but held together after cracking) and $(b)$ a prestressed panel (crack pattern highlighted for clarity and because prestressing straps partly conceal it).
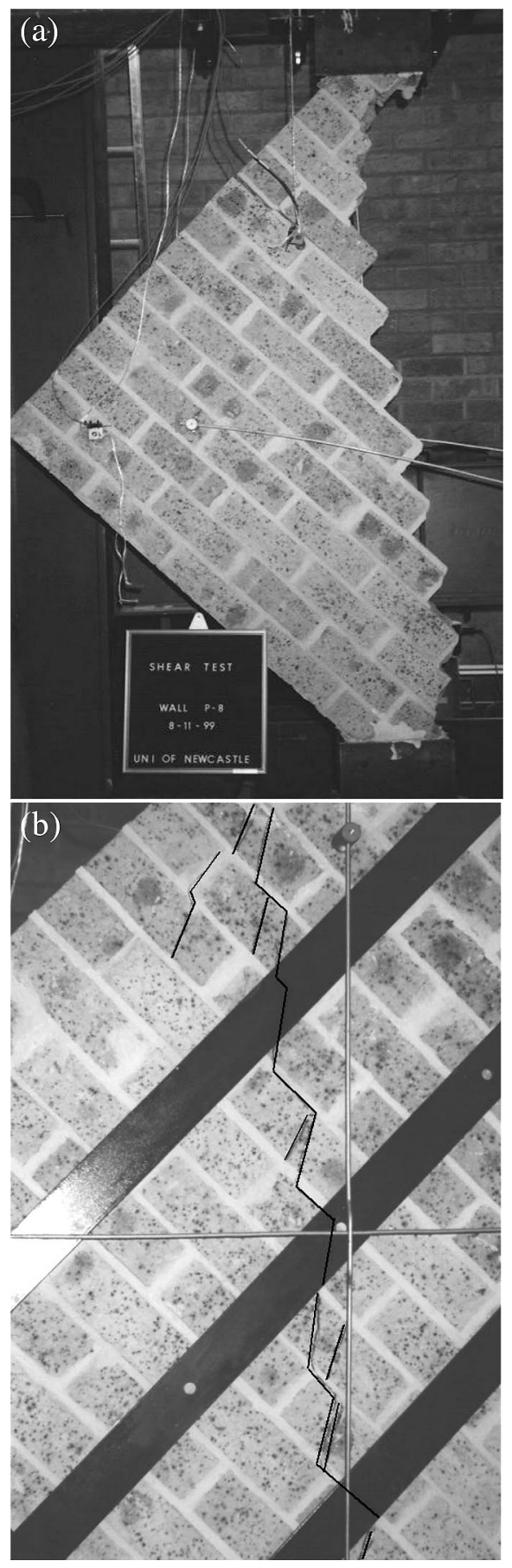

two walls, although significant differences in behaviour were observed. In the tied wall, the web-flange junction showed significant separation, which did not close when unloaded, indicating failure or slipping of the ties. In the bonded wall, however, there was no visible separation at the web-flange junction during or after the test. Bonding the web-flange connection with brickwork clearly increases the 
Fig. 11. Panel test data plotted by reinforcement type.

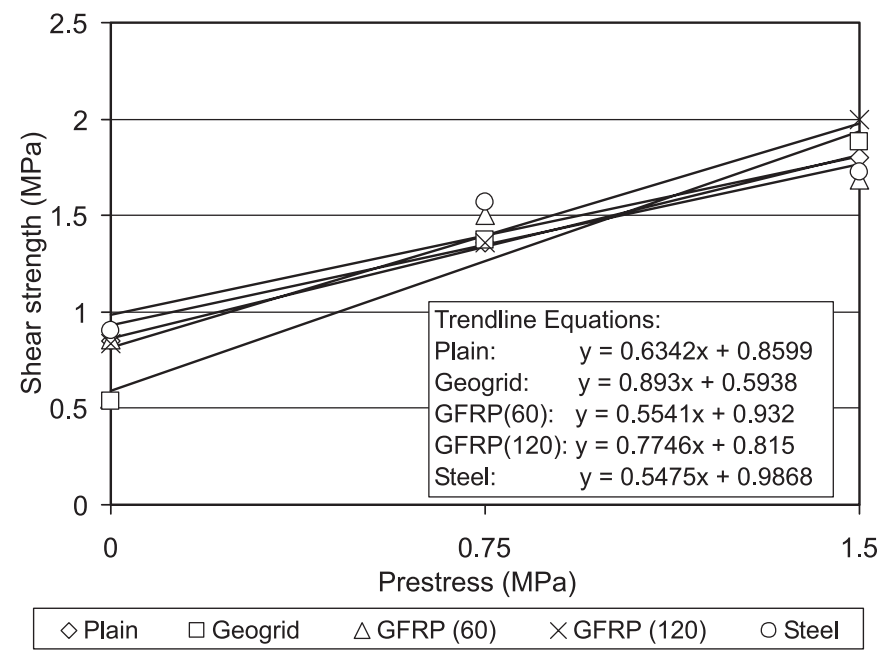

Fig. 12. All panel test data plotted with CSA S304.1-94 limits and limits from proposed design equation (Sayed-Ahmed et al. 1999).

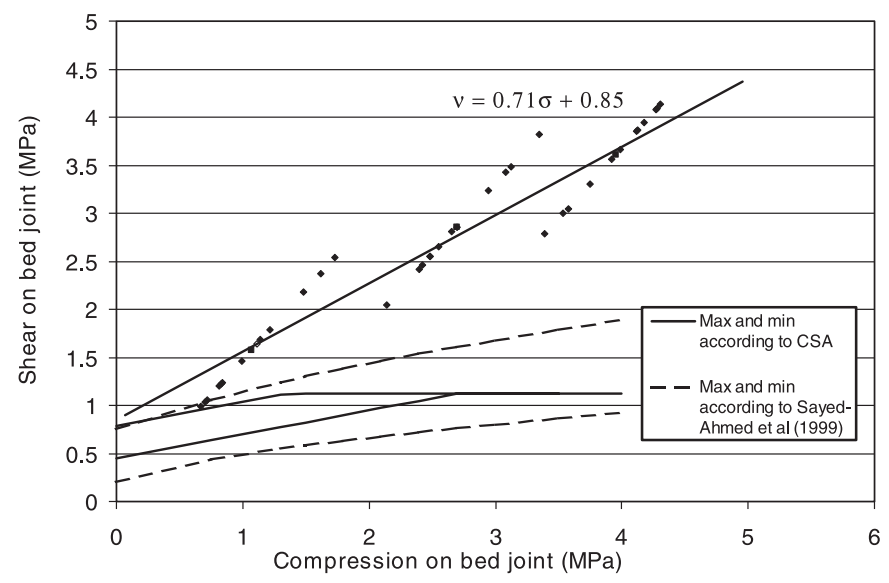

shear strength of this joint. The difference in behaviour due to bonding pattern required further investigation.

A series of specimens with $\mathrm{H}$-shaped cross sections was tested in an attempt to determine the effect of bond pattern on the strength of the web-flange intersection. The specimens were constructed using the same bricks and mortar as the shear panels. The same two types of GFRP strips were also tested as an alternative tie material. Two replicates each of five combinations of bonding and reinforcement were tested. A nominal compressive force, approximately equivalent to a normal floor load, was applied to the flanges to stabilize the specimen during and after the test. The deflection of the web was monitored during the test. Figure 13 shows the test arrangement. Table 3 lists the specimens, failure loads, and shearing stress on the section. While manufacturer's data for the shear strength of the GFRP material used were unavailable, another glass fibre product (ISOROD ${ }^{\mathrm{TM}}$ ) has a shear strength ranging from 163 to $206 \mathrm{MPa}$. The stresses obtained in the tests are of approximately the same magnitude (Table 3). Figure 14 shows typical failures of unbonded and bonded specimens. Note that in the unbonded
Fig. 13. Schematic of the test arrangement for web-flange connection shear tests.

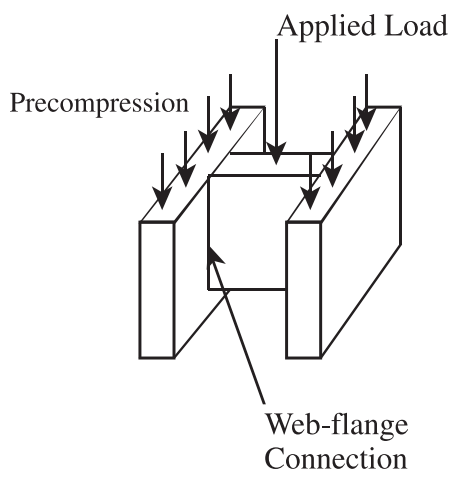

Table 3. List of H-shaped specimens, ultimate loads, and shear stresses.

\begin{tabular}{rllcc}
\hline Specimen $^{a}$ & $\begin{array}{l}\text { Type of } \\
\text { reinforcement }\end{array}$ & $\begin{array}{l}\text { Bonded/ } \\
\text { unbonded }\end{array}$ & $\begin{array}{l}\text { Ultimate } \\
\text { load } \\
(\mathrm{kN})\end{array}$ & $\begin{array}{l}\text { Shear } \\
\text { stress }^{b} \\
(\mathrm{MPa})\end{array}$ \\
\hline 1 & GFRP 60 & Unbonded & 38.3 & 159.5 \\
2 & GFRP 60 & Unbonded & 47.4 & 197.4 \\
3 & GFRP 120 & Unbonded & 59.8 & 124.5 \\
4 & GFRP 120 & Unbonded & 52.1 & 108.6 \\
7 & None & Bonded & 110.8 & 1.53 \\
8 & None & Bonded & 153.5 & 2.11 \\
10 & GFRP 60 & Bonded & 223.1 & 3.07 \\
6 & GFRP 60 & Bonded & 144 & 1.98 \\
5 & GFRP 120 & Bonded & 108.7 & 1.5 \\
9 & GFRP 120 & Bonded & 204.2 & 2.81 \\
\hline
\end{tabular}

${ }^{a}$ Specimens were numbered in order or testing.

${ }^{b}$ The shear area used to determine the shear stress was equal to the area of reinforcement for the unbonded specimens and equal to the joint area for the bonded specimens.

case there is a clean break of the mortar joints and failure of the ties, while in the bonded specimens there was failure in the bricks and buckling of the flanges due to the forces on the interlocking bricks.

The results of this small series of tests indicate that the mechanical interlock of a bonded web-flange connection provides a significant structural advantage over a tied connection. However, this advantage has its price. In a bonded wall, there is a clear interlock of the web and flange masonry. The flanges thus must be constructed in one third running bond to avoid a continuous vertical mortar joint in the flange at each intersection with a web (Fig. 2). The webs must be placed specific distances apart, dictated by the length of a unit. The advantage of a tied wall is that the webs can be placed anywhere along the length of the wall without reference to the running bond pattern of the flanges (Fig. 2). Tied diaphragm walls therefore have a continuous, relatively weak mortar joint at the web-flange junction. This joint is bridged by ties (usually stainless steel) and failure is governed by these ties yielding in flexure as the web and flange try to slide past one another. The maximum tie spac- 
Fig. 14. Typical web-flange connection failures for (a) GFRP tied (unbonded) connections and $(b)$ bonded connection.
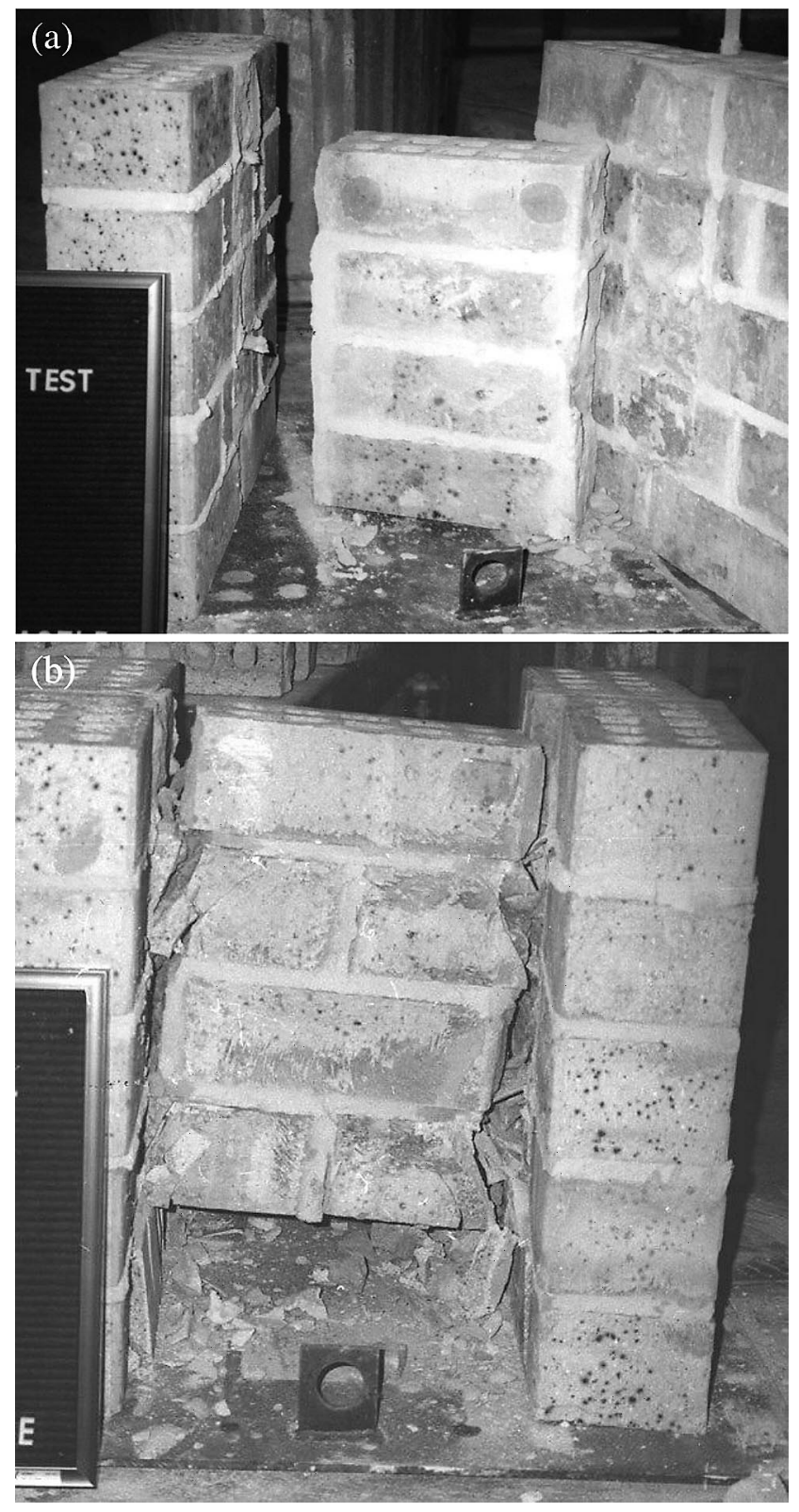

ing can be determined from the properties of the tie (Phipps and Montague 1986).

\section{Concluding remarks}

With the benefit of a non-corroding post-tensioning system such as with CFRP, post-tensioned masonry is an attractive alternative to other forms of construction. To broaden the scope of applications of structural masonry, particularly when post-tensioned, improvement in shear strength is required and provisions must be introduced to the Code to allow for the effects of bonding pattern and prestressing force on the shear resistance of masonry. Prestressing has a definite influence on the shear strength of masonry. This influence needs to be evaluated at higher prestress levels than described here. However, the ASTM E519 test apparatus seems unable to permit testing much beyond the maximum level described here because of localized compression failure in the load shoes. Further, its use as a shear rather than purely a splitting tensile test is questionable. The effects of bed reinforcement on shear strength as determined by this test do not appear to be significant except in post-cracking behaviour. The type of bonding in web-flange connections has a significant influence on the strength of this connection. The mechanical interlock of the bonded pattern provides a definite strength advantage, although the bond pattern is less flexible when these type of connections are incorporated into the structure. With improved shear resistance, CFRP post-tensioned masonry of geometric cross section will be a cost-competitive form of construction for many types of walls and should be recognized as such.

\section{Acknowledgements}

This work is supported by the ISIS Canada (Intelligent Sensing for Innovative Structures) Network of Centres of Excellence. We gratefully acknowledge this support. We also acknowledge I-XL Brick Supplies Ltd. and Mitsubishi Chemical Corporation for donating bricks, mortar, and CFRP tendons used to build and prestress the walls. The masons were provided with compliments of the Masonry Contractors Association of Alberta Southern Region: many thanks. The support of the Natural Sciences and Engineering Research Council of Canada is also greatly appreciated. The project in Newcastle was made possible because of the generosity of Boral Bricks Pty., Australia. Finally, special thanks to the technical staff of the Departments of Civil Engineering, University of Calgary and University of Newcastle, especially Mr. Dan Tilleman and Mr. John Noonan.

\section{References}

Allen, L.N. 1986. Post-tensioned brickwork at Rushden Fire Station. Engineers File Note \#1, Brick Development Association, Windsor, Berkshire, United Kingdom.

Bradshaw, R.E., Drinkwater, J.P., and Bell, S.E. 1982. A multipurpose farm building incorporating prestressed brickwork diaphragm walling. Proceedings of the British Ceramic SocietyLoad-Bearing Brickwork (7), Stoke-on-Trent, United Kingdom, No. 30, pp. 308-315.

BSI. 1995. Code of practice for use of masonry, Part 2: Structural use of reinforced and prestressed masonry, BS-5628: Part 2: 1995, British Standards Institute, London, United Kingdom.

Campbell, T.I., Shrive, N.G., Soudki, K.A., Al-Mayah, A., Keatley, J.P., and Reda, M.M. 2000. Design and evaluation of a wedgetype anchor for fibre reinforced polymer tendons. Canadian Journal of Civil Engineering, 27(5): this issue.

CSA. 1994. Masonry design for buildings (limit states design) structures (design). CSA- S304.1-94, Canadian Standards Association, Etobicoke, Ont.

Curtin, W.G., Shaw, G., Beck, J.K., and Bray, W.A. 1982. Posttensioned brickwork. Proceedings of the 6th International Brick Masonry Conference, Associazione Nazionale Degli Industriali dei Laterizi, Rome, Italy, pp. 961-970.

Curtin, W.G., Shaw, G., Beck, J.K., and Howard, J. 1989. Design of post-tensioned brickwork. Brick Development Association, Windsor, Berkshire, United Kingdom. 
Foster, D. 1970. Design and construction of a prestressed brickwork water tank. Proceedings of the 2nd International Brick Masonry Conference, Stoke-on-Trent, United Kingdom, pp. 287-294.

Ganz, H.R. 1996. VSL's experience with post-tensioned masonry. Proceedings of the Committee on Concrete and Masonry Structures Symposium, Structures Congress XIV, American Society of Civil Engineers, Chicago, Ill., pp. 25-36.

Garrity, S.W. 1995. Corrosion protection for prestressing tendons for masonry. Proceedings of the 7th Canadian Masonry Symposium, Hamilton, Ont., pp. 736-750.

Garrity, S.W., and Nicholl, R.D. 1994. Reinforced and prestressed masonry earth retaining walls - A cost study. Proceedings of the10th International Brick and Block Masonry Conference, Calgary, Alta., pp. 431-440.

Hanlon, J.R.G. 1970. Prestressed concrete masonry. Concrete, 4(9): 356-358.

Kirk, S.J. 1996. Life cycle costing reveals masonry's long-term value. Masonry Construction, 9(12): 555-557.

Lissel, S.L., Tilleman, D., Sayed-Ahmed, E.Y., and Shrive, N.G. 1998. Carbon fibre reinforced plastic (CFRP) prestressed masonry. Proceedings of the 8th Canadian Masonry Symposium, Jasper, Alta., pp. 610-621.

Lissel, S.L., Tilleman, D., Sayed-Ahmed, E.Y., and Shrive, N.G. 1999. Testing of a diaphragm wall post-tensioned with carbon fibre reinforced polymers (CFRP). Proceedings of the 8th North American Masonry Conference, Austin, Tex., June 1999, 12 p. on CD.

Lissel, S.L., Simundic, G., Page, A.W., and Shrive, N.G. 2000. Improving the shear resistance of masonry. Proceedings of the12th International Brick/Block Masonry Conference. Universidad Politecnica de Madrid, Madrid, Spain, June 2000, pp. 1075-1084.

Phipps, M.E., and Montague, T.I. 1986. The design of prestressed concrete blockwork diaphragm walls. Report No. (21.9) Fg2, Aggregate Concrete Block Association, Leicester, United Kingdom.

Sayed-Ahmed, E.Y., and Shrive, N.G. 1998. A new steel anchorage system for post-tensioning applications using carbon fibre rein- forced plastic tendons. Canadian Journal of Civil Engineering, 25(1): 113-127.

Sayed-Ahmed, E.Y., Lissel, S.L., Tadros, G., and Shrive, N.G. 1999. Carbon fibre reinforced polymer (CFRP) post-tensioned masonry diaphragm walls: prestressing, behaviour, and design recommendations. Canadian Journal of Civil Engineering, 26(3): 324-344.

Shaw, G., Curtin, W.G., Priestly, C.L., and Othick, G.J. 1988. Prestressed channel section masonry walls. The Structural Engineer, 66: 117-120.

Standards Australia. 1998. Australian standard-masonry structures. AS 3700-1998, Standards Association of Australia, Homebush, NSW, Australia.

\section{List of symbols}

$b$ the width of the webs (mm)

$C$ a compression force $(\mathrm{kN})$

$D$ the diagonal height of the panels ( $\mathrm{mm}$ )

$e$ the moment arm between $C$ and $T(\mathrm{~mm})$

$f_{\mathrm{m}}^{\prime}$ the characteristic 28-day strength of the masonry determined from prism compression tests (MPa)

$f_{\mathrm{p}}$ the compressive stress due to the prestressing (MPa)

$f_{\text {td }}$ the diagonal tensile strength of the masonry ( $\mathrm{MPa}$ )

$h$ the height of the wall ( $3 \mathrm{~m}$ in this case) $(\mathrm{m})$

$M$ the moment in the structure at a particular section $(\mathrm{kN} \cdot \mathrm{m})$

$N$ the force acting normal to the shear failure plane $(\mathrm{kN})$

$P$ the applied load $(\mathrm{kN})$

$S$ the force acting parallel to the shear failure plane $(\mathrm{kN})$

$t$ the depth of the section (mm)

$T$ a tensile force equivalent to the prestressing force $(\mathrm{kN})$

$V$ the shear force on the section $(\mathrm{kN})$

$W$ the self weight of the wall and the capping beam $(\mathrm{kN})$

$\theta$ the angle of the shear failure plane $\left(^{\circ}\right)$

$v_{m}$ the total shear strength of the masonry ( $\left.\mathrm{MPa}\right)$

$\mathrm{v}_{\mathrm{m}_{0}}$ the shear strength of the masonry with no prestress applied $(\mathrm{MPa})$ 